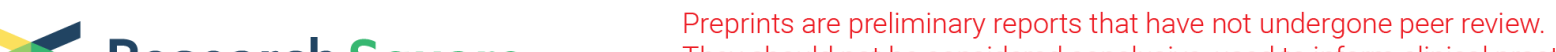 $\begin{array}{ll}\text { Research Square } & \text { They should not be considered conclusive, used to inform clinical practice, } \\ \text { or referenced by the media as validated information. }\end{array}$
}

\section{Analysis On Ecological Characteristics of Mississippian Coral Reefs in Langping, Guangxi}

\section{Dayong Yang}

Shenyang Jianzhu University

Honglun Chang ( $\nabla$ changhonglun@126.com )

Hebei GEO University

Xiao Liu

Shandong No.3 Exploration Institute of Geology and Mineral Resources

Peng Wan

Shandong No.3 Exploration Institute of Geology and Mineral Resources

Liming Shen

Shandong No.8 Exploration Institute of Geology and Mineral Resources

\section{Research Article}

Keywords: reef-building, palaeogeography, ecological, organism

Posted Date: January 10th, 2022

DOI: https://doi.org/10.21203/rs.3.rs-1218212/v1

License: (c) (i) This work is licensed under a Creative Commons Attribution 4.0 International License. Read Full License 


\section{Abstract}

Several Late Viséan-Serpukhovian coral reefs were identified in Langping, Tianlin. To further understand of environment that was suitable for the development of reef-building communities and the construction of coral reefs in Langping, in this paper, part of the reef-building environmental and the ecological characteristics of coral reefs then were recovered by analyzing the development settings, palaeogeography, sedimentation of reefs, the response to hydrodynamic conditions of reef-building corals, effects of disturbance and non-reef-building organism on reef communities, and the influence of coral morphology on reef development. The sedimentary environment of Langping in Late ViséanSerpukhovian is considered to be suitable for the development of benthic communities. The current appearance of reefs is determined by both coral populations ecological characteristics and reef-building environment.

\section{Introduction}

Several Early Carboniferouscoral reefs were identified in Yaoyunling formation and Du'an Formation in Xiadong village, Longjiangdong Village and Xinzhai Village, Langping Township, Tianlin County, Guangxi Province (Fig. 1). These reefs are of low maturity, with different scales and simple reef-building modes. However, the benthic communities and ecology of the reefs differ from other contemporaneous reefs of Carboniferous ${ }^{[1-2]}$.The discovery of these coral reefs is significant for supplementing the evolution sequence of carboniferous reefs and studying the development laws of the whole Carboniferous reef ecosystem $^{[1,3]}$. In a series of factors affecting the specific appearance and evolution of reefs, the habitat environment of reef-building communities is fundamental in controlling the overall characteristics of reefs, and is dominant during the process of reef development and evolution ${ }^{[4-6]}$. Simultaneously, the ecological characteristics are crucial to the appearance of reef ${ }^{[1]}$, while it lacks of associate studies. Based on field investigation, detailed analysis and careful demonstration, this paper makes research on reef ecological environment in the Langping and the ecological characteristics of the reef communities for decipheringthe various factors affecting the specific appearance of the Mississippian sub-shallow sea reefs.

Although the ecological conditions for reef development are generally similar, including temperature, water quality, light, nutrition, and oxygen, there are obvious differences on environmental factors and ecological features among reefs with diverse appearances. Such differences will result in significant diversities of reefs directly or indirectly ${ }^{[7-10]}$. Fang and Hou ${ }^{[11]}$ and Gong's research team ${ }^{[2,8,12-14]}$ have conducted significant research on many reefs in Langping. The palaeogeographic environment restoration of Langping is ideal for benthic communities, combining lithofacies recognition, biological fossil identification, and sedimentary microfacies analysis ${ }^{[12-13]}$. Several reefs developed in the study area are rare framework reefs of Late Viséan-Serpukhovian, which are different from synchronous reefs in other areas in biodiversity, building modes, continuity, maturity, scales and other specific features [2,13-14]. These characteristics are closely related to the unique environmental conditions and ecology of biological 
communities in the study area. Previous studies on the reef in Langping mainly analyzed the reef from the perspectives of paleontology, sediment and deposition. This paper discusses the direct or indirect shaping factors and influencing mechanism of reefs from the perspectives of environmental factors and biological communities.

\section{Sampling And Methods}

Field observation, identification, description, measurement, and photographing of four reef outcrops in Langping were carried out carefully. Lithology, sedimentary structure, stratum thickness and biological characteristics were documented in detail, and about 100 representative samples were collected. More than 130 thin sections, 30 polished slabs surfaces and 200 photos were taken in the lab in preparation for microfacies paleoecological analysis. These samples now are preserved in Department of Geology, Northeastern University, Shenyang, China.

\section{Reef overview}

The coral reef in Xiadong Village exposes in EW direction and developed into large reefs without obvious discontinuity and cycles. The reef is about $260 \mathrm{~m}$ in length and $50 \mathrm{~m}$ in height. Main builders consist of colony corals Diphyphyllum and Siphonodendron. There are significant vertical changes in the distribution of reef-building coral assemblages. Three successive reef-building coral assemblages, Diphyphyllum, Siphonodendron-Lithostrotion, and Diphyphyllum-Syringopora, can be clearly identified from bottom to top.

The multi-layer reef in Longjiangdong Village, which can be divided into three layers, extends nearly EW, with $27 \mathrm{~m} \times 3.8 \mathrm{~m}, 16 \mathrm{~m} \times 2.5 \mathrm{~m}$, and $40 \mathrm{~m} \times 9 \mathrm{~m}$ in length and thickness respectively. The builder Diphyphyllum constructs a framework for reef. Coral clusters have various scales with maximum of $2 \mathrm{~m} \times 3 \mathrm{~m}$ in height and width, most being vertical clusters.

Patch reef in Longjiangdong Village is small, whose outcrop is $11.2 \mathrm{~m}$ long and $6.2 \mathrm{~m}$ thick. The reef builders are colony Diphyphyllum, individual Caninia, and colony Lithostrotionella. The monomeric tetracoralla eventually formed an upper layer of the reef with $3 \sim 5 \mathrm{~m}$ of width.

The coral layer reef preserved in the east of Xinzhai Village is about $15 \mathrm{~m}$ long and 5 to $6 \mathrm{~m}$ thick. The colony Lonsdaleia formed a framework as the bottom of the reef, then overlaid by unidentified dendrimers and colony coral Antheria. Individual corals eventually formed the reef upper layer with the width of 3 to $5 \mathrm{~m}$.

\section{Results And Discussion}

This paper discusses four Late-Mississibian reefs in Langping. Based on the analysis, the development environment and ecology of reef communities are considered to have an important impact on the appearance of reefs. The study is limited by few actual data, inevitably there are omissions and mistakes. 


\section{Analysis of environmental conditions for reef development}

\section{Settings of reef development}

The F/F extinction event in Late Devonian caused the complete disorganization of the reef-building communities based on stromatoporoid-coral assemblage ${ }^{[15-16]}$. Microorganisms and algae reconstructed a new reef-building ecosystem after the mass extinction ${ }^{[17-18]}$. Some short-term biological frame reefs developed with low maturity, limited reef-building organisms, small sizes, and restricted distribution ${ }^{[19]}$. Carboniferous is widely considered as a non-ideal period for frame reefs. And harsh climate and marine conditions occurred in Mississippian, including extensive marine hypoxia, repeated glacial and interglacial climate changes, and frequent changes of sea level and in seawater surface temperature, which may hinder the recovery of Early Carboniferous metazoan reefs ${ }^{[16,20]}$.

In Early Viséan, metazoans gradually began to participate in reef building. In the middle and late stage of Viséan, a large number of biological build-ups formed by corals and bryozoans began to appear, including a small number of sponge reefs/mounds. The abundance and biodiversity of the Mississippian metazoan reefs were prosperous in Late Viséan. Corals, bryozoans, sponges, calcareous microorganisms, and some calcareous algae became the main builders in this period ${ }^{[3]}$. Although most of the Viséan metazoan reefs are tabular or laminar, large-scale reefs can also be seen in some areas. Therefore, after the complete disintegration at the end of Devonian and the downturns at the beginning of Carboniferous, metazoan framework reefs are considered to revive in the middle and late stage of Viséan, , due to the occurrence of relatively warm climate conditions and high sea level ${ }^{[16]}$.

Therefore, the coral reefs in the study area are the products of shallow benthic community in relatively good conditions of Late Viséan-Serpukhovian, which is common for reef evolvement with times ${ }^{[16]}$. Thus, it is expected that more synchronous reefs would be identified in southern China, or even in the study area in the future.

\section{Paleogeography of reefs}

Langping is located in Dian-Qian-Gui Basin ${ }^{[21]}$ regionally (Fig. 2), in the eastern end of Tethys tectonic domain and at the interjunction of Tethys and Pacific structure globally. Dian-Qian-Gui Basin was adjacent to Tethys basin in Carboniferous. During the Early Carboniferous, Gondwana moved closely to the equator but was separated from the northern continent by Tethys, in which the tropical current flowed freely from east to west. On both sides of the shallow shelf of Tethys, the benthic warm-water organisms distributed widely with high abundance and diversity.

Viséan-Serpukhovian experienced dramatic climate changes and widespread glaciation ${ }^{[24]}$. However, the Viséan is also the key layer of various biological structures with abundant coral reefs, showing a high diversity of shallow marine benthic communities, which peaked during Late Viséan. In Tianlin, the newly identified metazoan reefs are concentrated in Late Viséan-Serpukhovian, which is consistent with 
frequent sea-level fluctuations and possible glacial changes. It seems contrasting that tropical coral communities developed during glacial period. However, recent studies suggest that the persistent warm ocean currents on the platform helped some coral species survive in Carboniferous glacial events ${ }^{[25]}$. Although contemporaneous coral reefs are poorly developed in other areas, Tianlin might provide an ecological refuge related to ocean currents for corals ${ }^{[26]}$.

\section{Sedimentation of reef development}

According to the regional geological structure, the slope model for Langping paleocarbonate platform is obviously different from that of steep slope platform margin, which can be directly affected by waves. Langping palaeo-platform can be seen as one of the small blocks (block fault barrier) separated from a large platform (continental margin sea basin) ${ }^{[11]}$. The relative position of these blocks is crucial for the emergence and growth of reefs.

It is common to see the in-situ fine-grained micrite limestone and argillaceous limestone formed in weak hydrodynamic conditions in Langping, with poorly developed evaporites. There are patch reefs and reef layers indifferent sizes in the wide intraclast beach, where obviously developed reef beach complexes are rare. It has not been observed that there are fragments of carbonate base broken by storm in the clastic beach. Based on sedimentary characteristics, the study area is considered to be gentle-slope open

platform ${ }^{[27-28]}$. It suggests that the study area is far away from the margin of steep-slope platform directly affected by the waves, and belongs to internal environment of gentle-slope platform.

These gentle-slope platforms under deep water have low water energy, while the high strong water at shore leads to the development of coarse-grained bioclastic beaches and a few patch reefs. The beaches are irregular-shaped due to long term transportation and reformation effects of waves and water flow, showing low and gentle slope angles. Disperse reef-beach complexes at the platform margin have little impact on inner-platform seawater and the water flows smoothly ${ }^{[29]}$.

Thus, the reefs in Langping can be considered to develop in shallow beach of platform intertidal zone. The seawater around Langping carbonate platform in Late Viséan-Serpukhovian was relatively shallow while the water flow was strong. Bones of crinoids, brachiopods, a few foraminifera, and individual corals were broken by strong ocean currents, and deposited in situ with a small amount of gravels and lime-mud (Fig. 3). The clastic beach was unstable. Its cause lies in the lack of sufficient cohesive and consolidated organisms, large-scale and effective wave-resistant structure could not be formed quickly without them ${ }^{[30]}$. Besides, in the vast platform, the week impact of water led to mud-lime sedimentation, which was unfavorable for most benthos. However, bondstone was more likely to be formed by some binding algaes in the platform (Fig. 4). Therefore, neither the surrounding or the inner region of the platform could provide a friendly living conditions for coral reefs to develop stably in long term. The gentle-slope platform environment in Langping result in obvious differences in terms of growth sizes, wave resistance and reef-building ability between corals in the study area and those on the steep-slope platform margin. 
At the same time, a number of advantages, including warm climate in Late Viséan-Serpukhovian, good seawater circulation around Langping platform, sufficient oxygen, and nutrients supply, promoted the reef-building corals to grow. Such favorable conditions led to uplifts to be formed on clastic beach, including patch reefs and reef layers with certain sizes. These uplifts could barrier waves and provided a protected environment though they were much smaller than that developed at the steep-slope platform margin. The inhabitants on the beach could not resist strong waves. Therefore, these uplifts called reefbeach complex could only stand against waves and currents passively ${ }^{[28]}$. Besides, they were essentially different from the framework coral reefs which developed on steep-slope platform margin in hydrodynamic conditions, nutrient sources, reef sizes, and growth rates.

Another potential favorable factor for the study area may be the deep-water area of gentle slope, which could provide more stable conditions and reduce the destructive impact of global glacial events and large-scale sea-level fluctuations on reef-building communities ${ }^{[24]}$. The frequent fault activities in DianQian-Gui basin caused the rise and fall of equivalent sea level. More influence of sea-level fluctuations and hydrodynamic conditions would be exerted on Langping platform due to its small size Furthermore, reef growth promoted by reef-building communities would be frequently disturbed. The sediments with multicycle, different components, and diversely fragile clasts in the study area is the direct evidence of frequently changing environment.

Alternatively, the sedimentary environment of Langping platform provided necessary conditions for the benthic communities, which were favorable for reef-building communities to develop and reefs to grow rapidly, containing the factors of preventing them from rapid and stale growth. These factors directly or indirectly determined the ecology of reef-building communities and the general appearance reef development in the study area.

Overall, the environmental factor is the primary factor affecting the overall development trend of reefs.

\section{Ecological characteristics of reef communities}

\section{Response of reef-building corals to hydrodynamic conditions}

Among factors that limit the development of coral reefs, hydrodynamic condition is a very important factor, which directly determines the survival and prosperity of each reef-building population, being the straightforward factor affecting the sedimentation and reef growth. This is particularly conspicuous in Langping. The reef-building corals have also changed to a certain extent corresponding to variational hydrodynamic conditions. Based on analysis of the vertical sediments and microfacies changes of coral reefs in the study area ${ }^{[31]}$, the hydrodynamic condition changes during the development of reefs are inferred. Combining the evolution of reef-building communities with the study, the adaptation process of reef-building corals to hydrodynamic conditions is recovered.

Xiadong coral reef started with colonization and expansion of Diphyphyllum larvas on the bioclastic hard substrates $^{[32-33]}$. They grew vertically into upright clusters and were insensitive to low-concentrated 
sediments contained in relatively calm water environment ${ }^{[34]}$. With the continuous increase of the water energy, the relatively dense clumped Siphonodendron and massive Lithostrotion became more adaptable to the turbulent water environment, becoming dominating, while Diphyphyllum playing a subordinate role. Siphonodendron-Lithostrotion assemblage stopped growing after a flourishing period due to the failure to adapt to the increasing hydrodynamic conditions. Diphyphyllum, which had been existing in the biological community, combining with Syringopora, to maintain the growth of the reef. However, this assemblage was declined as a result of strong hydrodynamic conditions. And it finally died out for continuous falling of sea level. Consequently, the reefs stopped growing.

Longjiangdong multi-layer reef is composed of three relatively independent flat units of reef layer. Diverse species are identified in the reef, while colony coral Diphyphyllum contributes greatly to reef growth. Diphyphyllum clusters colonized in patchy form on substrates which are composed of bioclasts or lithic gravels. After a period of growing, the first reef-building process was quickly ended by high-energy water. Then favorable conditions occurred and Diphyphyllum restarted to bloom extensively. In this unit, Diphyphyllum clusters grew closely against strong currents and the individuals were larger and sparsely spaced than those in lower unit. Later, Diphyphyllum was disturbed by high energy water brought by short-term rise and fall of sea level, growing only in restricted suitable area. Afterwards, the environment was improved, and Diphyphyllum expanded rapidly to take up more living space. As a result, the upper unit of Longjiangdong coral reef was formed, in which Diphyphyllum individuals were slightly larger than those in the first two units.

Longjiangdong patch reef started to develop in a relatively deep water environment. Diphyphyllum initially colonized and expanded in favorable conditions with the increase of water energy. Then the reef-builders transferred from single coral to an assemblage of Diphyphyllum-Caninia-Lithostrotionella. These three corals grew independently and contributed almost equally to the reef framework. However, this coral assemblage was not stable enough in community structure and function. It has been easily influenced by the weakening hydrodynamics and the increasing sedimentation, only building small patch reefs.

Xinzhai layer reef was initialized by colonization and expansion of Lonsdaleia on bioclastic beach. Large coral clusters were formed to resist turbulent water. With the weakening of hydrodynamic conditions, an unknown branchlike organism and Antheria communities continued to develop separately in this area. Slender branchlike organisms expanded rapidly in such a low-energy water environments until they were replaced by some individual corals after an increasing hydrodynamics. In this layer reef, each builders had to depart from the reef due to rapidly changed hydrodynamic conditions just at the beginning of colonization and expansion.

The evolution of reef-building corals in these four reefs indicates that both the coral assemblages and coral individuals would constantly adapt to the changing hydrodynamic conditions in Langping. Although it is passive adjustment for the coral population to correspond to the long-term effects of the environment, it is obviously positive for the construction and development of the coral reefs. 


\section{Impact of disturbance on reef communities}

Disturbance is a relatively discontinuous event, which is ubiquitous in nature. It may indirectly affect the composition and population relationship of reef communities by changing the environmental conditions, thus affect the structure and function of reef communities, even the evolvement of the reef ${ }^{[35]}$. The major disturbances of Mississippian framework reefs consist of frequent fluctuation of sea level, the abrupt changes of water flow, and drastic changes of climate and weather. These seem to be much obvious in Langping platform due to its small size, which exert more frequent influence on the reef communities in the study area.

The most direct impact of disturbance events for reef is the interruption in continuously evolving reef communities, which is common in reef studies. After the interruption caused by disturbances, some communities gradually recover due to the absence of continuous disturbance, or to be substituted by invading communities. The winner after interruption is decided by random factors to a large extent, which is called competitive lottery ${ }^{[36]}$. The competitive lottery requires the approximately equal invading ability and endurance of environmental conditions in interruption of invaders.

Certainly, low-intensity disturbance does not necessarily produce discontinuity, but medium-intensity disturbance without discontinuity could directly impact on community species diversity. According to "Moderate disturbance hypothesis", moderate disturbance is conducive to a higher level of community diversity ${ }^{[37]}$. In environmental conditions with moderate intensity of disturbance, most species will not disappear due to frequent disturbance, and the dominant pioneer species will also be restrained by disturbance to a certain extent, so large number of species can coexist, attaining the highest diversity ${ }^{[35]}$.

The reef-builders in Langping are diverse. More than 4 reef-building corals are identified in Xiadong reef, while 4 and 3 are in Xinzhai layer reef Longjiangdong patch reef respectively. These reef-building corals, mostly Diphyphyllum, Lithostrotion, Siphonodendron and Lonsdaleia, distributed irregularly in the reefs. Their ecological niche and function were similar and none of them was obviously dominant in the community (Fig. 5). These are coincident with theory of competitive lottery and moderate disturbance hypothesis, which is the direct consequence of disturbance events.

Ecosystem is a dynamic complex system, which could maintain the original structure and function through self-regulation, when subject to small disturbance ${ }^{[37]}$. The stability of classic reef ecosystem includes the ability of the ecosystem to resist external disturbance and to recover to the initial state after disturbance was removed ${ }^{[38]}$. Although ecosystem stability is not absolutely corresponding to biodiversity, it is generally accepted that communities with high diversity are always more stable $\mathrm{e}^{[35]}$.

There have been no reef-building corals with strong resistance and rapid recovery ability in the communities in Langping. None of these corals succeeded in developing into the dominant species that could build reef frames. This made the reefs in Langping mostly appear in the form of small patch reefs or reef layers. However, formation of large reef in Xiadong Village, patch reef in Longjiangdong Village, 
and layer reef in Xinzhai Village all relates to high diversity of reef-building corals. Different coral assemblages could effectively match changing hydrodynamic conditions and maintain reef growth.

Species diversity increased by disturbance stabilized the ecosystem, and this has been effectively verified during the construction of coral reefs in Langping.

\section{Effects of non-reef-builders on reef-building corals}

Besides reef-building corals, there are a large number of reef-dwellers and exo-reef organisms in the study area. Reef-dwellers refer to the species that do not directly contribute to reef growth in the community, mainly including various benthos and algaes ${ }^{[39]}$. Exo-reef organisms do not belong to reef-building communities, but they also play an important role in participating in energy flow and providing organic matter for the reef ecosystem ${ }^{[40]}$. Non-reef-building populations can affect the appearance and composition of reef-building communities, which are related to the status of reef-builders.

The common reef-dwellers and exo-reef organisms in Langping include crinoids, brachiopods, gastropods, various algaes, foraminifera, bryozoans, and some individual corals. Crinoids are absolutely dominant in amount of them.

Carboniferous echinodermata in Guangxi Province reached its peak in Middle-to-Late Mississippian. In terms of amount and distribution, thick limestone with echinodermata debris in carbonate platform are often dominated by crinoids ${ }^{[41]}$. Crinoids were fixed to the substrate by sessile organs or in other ways ${ }^{[42-}$ ${ }^{43]}$, which relied on organic particles in the water flow ${ }^{[44-45]}$. The identical ecological niche of crinoids with other metazoans, such as reef-building corals, resulted in competition for limited living space and food resources. Crinoids could grow in various environments ${ }^{[46]}$ for its adaptability to the environment. The large number of crinoids in Langping excluded other metazoans and restricted the development of benthic reef-builders in Late Viséan-Serpukhovian in Langping, leading to poorly developed reef-building communities.

Microorganisms and algaes could not fix on the moving clastic beach in frequently disturbed water. There has not been obvious evidence of extensive "algal turf" in the coastal area of Langping platform. And only a few corals bonded by algal mats were observed ${ }^{[47]}$ (Fig. 6). Apart from great contribution to primary productivity, a large number of algaes are also considered to play an important role in two aspects for coral reef ecosystem. One is to promote reef construction by its own binding and consolidation ${ }^{[48-49]}$. The other is to create a good condition for zoobenthos larvae to dwell and develop, thereby improving species diversity ${ }^{[50]}$. The algaes of poor population and quantity in Langping limited coral reef to a relatively low nutritional level, which was difficult to support extensive metazoans. Thus, diverse reef-building patterns such as bonding, binding, winding could not be implemented by algaes and other metazoans ${ }^{[51-52]}$. The reef framework in the study area was not stable enough to stand against strong water flow, and the biological communities could not deal with frequent environmental changes, which were directly related to poor development of algaes. 


\section{Influence of coral morphology on reef development}

In reef growth, the accumulation of reef has obvious impact on communities. Large reef could hold high diversity and quantity of inhabitant by improving local environment and creating diverse conditions. Consequently the reef-building communities are promoted in anti-disturbance and recovery, stabilizing reef construction. In terms of large reef, the framework-building corals would play a key role in reef construction regardless of which kind of patterns is adopted. Therefore, reef-building corals with large size, rapid growth, and strong resistance would become the biggest contributors to reef frame construction.

The main reef-building corals in Langping are composed of Diphyphyllum, Lithostrotion, Siphonodendron, and Lonsdaleia, etc, being the dominant builders. These corals are similar in morphology such as cluster colony, thick and strong skeleton, and densely packed individuals (Fig. 7), which enable them to resist water flow. At the same time, the upright colonies are adaptable to relatively calm water, being insensitive to mud deposition. In general, the main reef-building corals in the study area could be adaptive to the distinct water conditions. The ecological features of corals matched the gentle slope environment with deep water and rapidly changing flow energy in Langping. These cluster corals could colonize hard substrates and expand rapidly, thus the surrounding environment was changed. With a large amount of benthos grouped into reef-building communities, the visible carbonate uplifts were formed. These distinct uplifts constructed by coral clusters in different water conditions are composed of coral reefs of different sizes and appearance in the study area.

Complex and diverse local environments created by large reefs could significantly increase the benthos and improve species diversity in coral reefs. As a result, the nutrient flow in the community becomes complicated, and nutrients could be recycled effectively by reducing loss caused by water flow. Therefore, the overall productivity of large coral reef communities is always high. Complex trophic structure satisfied most of the benthos in the community with sufficient nutrients and inorganic salts. It divided inhabitants inside the reef from surrounding crinoids for food. And the former benefited more from the reef ecosystem. Therefore, the reef-building corals in large reefs show obvious growth advantage compared with crinoids.

The morphology of reef-building corals in Langping could enable them to become predominant species in various water environment. This promoted the continuous doming growth of reefs and brought a good cycle for reef-building communities to develop, which finally constructed various reefs. It suggests that the morphology of reef-building corals is the prerequisite for reef development.

In summary, reef communities are always limited and affected by environmental conditions. However, the ecology of the inhabitant are also important factors for shape reefs.

\section{Conclusions}


Based on the knowledge of the environment of Late Viséan-Serpukhovian coral reefs in Langping and the analysis of the ecology of reef communities, new understanding of the influencing factors and action mechanism of reefs can be summarized as follows.

(1) The conditions including relatively warm climate and high sea level in Late Viséan-Serpukhovian, and the long-term stable tropical ocean currents provided by open Tethys enabled the reef-building corals in the Langping to survive and build reefs in the unfavorable environment.

(2) The gentle slope of Langping platform provided the necessary conditions for the benthic communities. And water environment determined the general appearance of reefs in the study area.

(3) The adaptation of reef-building corals to hydrodynamic conditions is positively significant to the continuous construction of coral reefs.

(4) It is confirmed that disturbances could increase the species diversity of reef communities and enhance the stability of ecosystem.

(5) Large number of crinoids and the limited algaes lived in Langping are negative for nourishment of reef communities and growth of reefs.

(6) The morphology of the main reef-building corals enabled them to adapt to the water environment in the study area and to consequently build reefs in different sizes.

\section{Declarations}

\section{Acknowledgements}

The authors thank Dr. Xiaohong Chen for providing related photos.

\section{Authors' contributions}

DY conceived the research concept, then drafted and revised the manuscript. $\mathrm{HC}$ polished the language. $\mathrm{XL}$, and $\mathrm{PW}$ and $\mathrm{LS}$ sorted the materials respectively. All authors read and approved the final manuscript.

\section{Funding}

There is no funding for this paper.

\section{Availability of data and materials}

These materials were stored in the Department of Geology, Northeastern University, Shenyang, China. The datasets used during the current study are available from the corresponding authors on reasonable request.

\section{Competing interests}


The authors declare that they have no competing interests.

\section{Author details}

1. School of Transportation Engineering, Shenyang Jianzhu University, 110168, Shenyang, China;

2. Experimental and Practical Teaching Center, Hebei GEO University, 050031, Shijiazhuang, China;

3. Shandong No.3 Exploration Institute of Geology and Mineral Resources, 264011, Yantai, China;

4. Shandong No.8 Exploration Institute of Geology and Mineral Resources, 276800, Rizhao, China.

\section{References}

1. Gong, E., Zhang, Y., Guan, C. \& Chang, H. Main features of the Carboniferous organic reefs in the world. Journal of Palaeogeography 12(2), 127-139 (2010).

2. Chen, X., Gong, E., Wang, T., Guan, C., Zhang, Y., Yang, D. et al. The basic characteristics of Early Carboniferous coral reef at Xiadong Village in Tianlin, Guangxi, and its sedimentary environment. Acta Geologica Sinica 87(5), 597-608 (2013).

3. Yao, L. \&Wang, X. Distribution and evolution of Carboniferous reefs in South China. Palaeoworld 25, 362-376 (2016).

4. Barash, M. Environmental conditions as the cause of the great mass extinction of marine organisms in the Late Devonian. Dokl Earth Sci 475, 845-848 (2017).

5. DeCarlo, T., Cohen, A., Wong, G., Shiah, F., Lentz, S., Davis, K. et al. Community production modulates coral reef $\mathrm{pH}$ and the sensitivity of ecosystem calcification to ocean acidification. Journal of Geophysical Research, Oceans 122, 745-761 (2017).

6. Gouezo, M., Golbuu, Y., Fabricius, K., Olsudong, D., Mereb, G., Nestor V. et al. Drivers of recovery and reassembly of coral reef communities. Proceedings of the Royal Society B: Biological Sciences, 286 (2019). https://doi.org/10.1098/rspb.2018.2908.

7. Zhang, Y., Gong, E., Wilson, M., Guan, C. \& Sun, B. A large coral reef in the Pennsylvanian of Ziyun County, Guizhou (South China): the substrate and initial colonization environment of reef building corals. Asian Earth Sci, 37, 335-349 (2010).

8. Yang, D., Gong, E., Chen, X. \& Guan, C. Comparison of the late carboniferous reef community ecosystem in Guizhou and Guangxi. Journal of Northeastern University (Natural Science), 35(1), 107-111 (2014).

9. Zhang, Y., Gong, E., Huang, W., Wilson, M., Guan, C., Li, X. et al. Factors controlling the development of Fomichevella coral bioconstructions in the Gzhelian-Asselian (Late Pennsylvanian-early Permian) of Houchang, southern Guizhou, southern China. Palaeobiodiversity and palaeoenvironment. https://doi.org/10.1007/s 12549-020-00431-6. (2020). 
10. Maillet, M., Huang, W., Li, X., Yang, Z., Guan, C., Zhang, Y., et al.. Late Pennsylvanian carbonate platform facies and coral reef: new insights from southern China (Guizhou Province). Facies, 67, 3 (2021). https://doi.org/10.1007/s 10347-020-00613-w.

11. Fang, S. \& Hou, F. Bryozoan-coral patch reef of Datang age Carboniferouse period of Langping, Tianlin County, Guangx Province. Journal of Southwest Petroleum Institute, 4, 1-15(1985).

12. Chen, X., Gong, E., Wang, T., Guan, C., Zhang, Y., Yang, D. et al. The ecological function of crinoid in the Carboniferous reefs in Tianlin, Guangxi. Geological Review, 59(3), 446-453(2013).

13. Yang, D., Gong, E., Sun, B., Chen, X., Guan, C. \& Zhang, Y. Longjiangdong coral reef palaeoecology of the upper carboniferous Huanglong formation in Tianlin county, Guangxi province. Acta Sedimentotlgica Sinica, 31(3), 404-412(2013).

14. Gong, E., Yang, D., Chen, X. \& Guan, C. The Late Carboniferous Reefs Palaeoecology Characteristics of Langping, Tianlin County, Guangxi Zhuang Autonomous Region. Geological Review, 60(3), 1-14 (2014).

15. Copper, P. Ancient reef ecosystems expansion and collapse. Coral Reefs, 13, 3-11 (1994).

16. Yao, L., Aretz, M., Wignall, P., Chen, J., Vachard, D, Qi, Y et al. The longest delay: Re-emergence of coral reef ecosystems after the Late Devonian extinctions. Earth-Science Reviews. https://doi.org/10.1016/j.earscirev.2019.103060 (2019).

17. Stanley, G. The history and sedimentology of ancient reef systems. New York: Kluwer Academic(Plenum Publishing, 2001).

18. Qi, W.\& Fan, J. Evolution history of reef ecosystem and evolution of earth environment. Earth Science Frontiers (China University of Geosciences, Beijing), 9(3), 124 (2002).

19. Gong, E.\& Guan, G. Carboniferous Extinction and Influence on Evolution of Reef Communities. Journal of Northeastern University (Natural Science), 19(2), 122-124 (1998).

20. George, R., Peter, M., David, J., Mary, L. Ecological ranking of Phanerozoic biodiversity crises: The Serpukhovian (early Carboniferous) crisis had a greater ecological impact than the end-Ordovician. Geology, 40(2), 147-150 (2012).

21. Mei, M. \& Li, Z. Sequence-stratigraphic Succession and Sedimentary-Basin Evolution from Late Paleozoic to Triassic in the Yunnan-Guizhou-Guangxi Region. Geoscience, 18(4), 555-563 (2004).

22. Feng, Z., Yang, Y.\& Bao, Z. Llithofacies paleogeography of the Carboniferous in south China. Journal of paleogeography, 1(1), 75-86 (1999).

23. Yao, L., Wang, X., Lin, W., Li, Y., Kershaw, S.\& Qie, W. Middle Viséan (Mississippian) coral biostrome in central Guizhou, southwestern China and its palaeoclimatological implications. Palaeogeography, Palaeoclimatology, Palaeoecology, 448(SI), 179-194 (2016).

24. Wang, Z.\& Yang, F. Carboniferous paleobiogeography and palaeoclimate of China. Earth Science, 13(5), 495-502 (1988).

25. Maillet, M., Huang, W., Miao, Z., Gong,E., Guan, C., Zhang, Y. et al. Coral reefs and growth dynamics of a low-angle Carboniferous platform: records from Tianlin, southern China. Sed Geol. 
https://doi.org/10.1016/j. sedgeo.2019.105550 (2020).

26. Gouezo, M., Golbuu, Y., van Woesik, R., Rehm, L., Koshiba, S. \& Doropoulos, C. Impact of two sequential super typhoons on coral reef communities in Palau. Mar. Ecol. Prog. Ser. 540, 73-85. (doi:10.3354/meps11518) (2015).

27. Gu, J., Ma, F. \& Ji, L. Types, characteristics and main controlling factors of carbonate platform. Journal of Palaeogeography, 11(1), 21-27 (2009).

28. Xu, W. Depositional models of gently sloping carbonate platforms: A case study of the Middle-Upper Jurassic Karlof-Oxfordian in the Amu River Basin, Turkmenistan. Chengdu: Chengdu University of Technology (2013).

29. Guo, Q. Identification of reef-beach body and comprehensive study of sedimentary reservoir of Xiaohaizi Formation in Bamai area. Xi'an: Northwestern university (2012).

30. Ma, Z., Liu, W., Zhang, W. \& Li, B. Transition of Carbonate Ramp to Rimmed Platform: A Case Study from the Lower Cambrian Qingxudong Formation at the Majiang Section in Eastern Guizhou. Geological Science and Technology Information, 32(4), 43-49 (2013).

31. Ma, Y. Carbonate microfacies-analysis, interpretation and application. Beijing: Geological Publishing House (2006).

32. Chen, Y. Paleoecological characteristics of hard substrate environment. Mineral and Rock, 5(3), 141151 (1985).

33. Taylor, P. \& Wilson, M. Palaeoecology and evolution of marine hard substrate communities. EarthScience Reviews, 62, 1-103 (2003).

34. Chen, Y. Marine benthic palaeoecology. Beijing: Ocean Press (1991).

35. Mao, Z. \& Zhu, J. Effects of disturbances on species composition and diversity of plant communities. Acta Ecologica Sinica, 26(8), 2695-2701 (2006).

36. Connell, J. Diversity in tropical rain forest and caral reefs. Science, 199, 1302-1310 (1978).

37. Zhang, T., Gao, W. \& Lan, G. Application of systematology to reef paleoecology reseach. Journal of Southwestern Petroleum Institute, 13(4), 1-8 (1991).

38. Huang, J. \& Han, X. Biodiversity and ecosystem stability. Chinese Biodiversity, 3(1), 31-37(1995).

39. Wiedenmayer, F. Modern sponge bioherm of the Great Bahama Bank. Eclogae Geologicae Helvetiae, 71, 699-744 (1978).

40. Flügel, E. Microfazielle Untersuchungsme thoden vonkalken. Berlin: Springer, Abb (1978).

41. Thomas, W. \& Williami, A. The "Age of Crinoids": A Mississippian Biodiversity Spike Coincident with Widespread Carbonate Ramps. Palaios, 21, 238-248 (2006).

42. Grimmer, J., Holland, N. \& Messing, C. Fine structure of the stalk of the bourgueticrinid sealily Democrinus conifer (Echinodermata: Crinoidea). Marine Biology, 81, 163-176 (1984).

43. Yan, X., Mao, Y., Zhao, Y., Peng, J. \& Wu, M. The holdfasts of eocrinoids in Cambrian, Guizhou Province. Acta Palaeontologica Sinica, 49(3), 380-388 (2010). 
44. Guensburg, T. \& Sprinkle, J. Rise of echinoderms in the Paleozoic evolutionary fauna: Significance of paleoenvironmental controls. Geology, 20, 407-410 (1992).

45. Kerri, A. \& William, I. Paleoecology of Framebuilders in Early Silurian Reefs (Brassfield Formation, Southwestern Ohio). Ausich Palaios, 17, 237-248 (2002).

46. Yang, S. Paleoecology-Principle and Method. Beijing: Geological Publishing House (1993).

47. Cai, F., Chen, W. \& Lu, Y. Coastal water ecology. Beijing: Ocean Press (1989).

48. Ken, P. The Growth and Ecology of Upper Cambrian Microbialite Biostromes from the Notch Peak Formation in Utah. California: Lomalinda University (2016).

49. Huang, W., Zhang, Y., Guan, C., Miao, Z., Chen, X., Yang, Z., et al. Role of calcimicrobes and microbial carbonates in the Late Carboniferous (Moscovian) mounds in southern Guizhou, South China. Journal of Palaeogeography, 8, 26(2019).

50. Lei, X., Huang, H. \& Huang, L. Current state of ecological functions of coralline algae in coral reef ecosystem. Ecological Science, 31(5), 585-590 (2012).

51. Wu, Y. Paleoecology of Permian reefs in Guangxi and Guizhou. Oil and gas geology, 15(3), 201-209 (1994).

52. Lu, T., Wen, Y., Qiang, Z., Fan, J. \& Wen, C. Reef-building model for the Permian organic reefs in South China. Lithofacies Paleogeography, 18(2), 16-19 (1998).

\section{Figures}




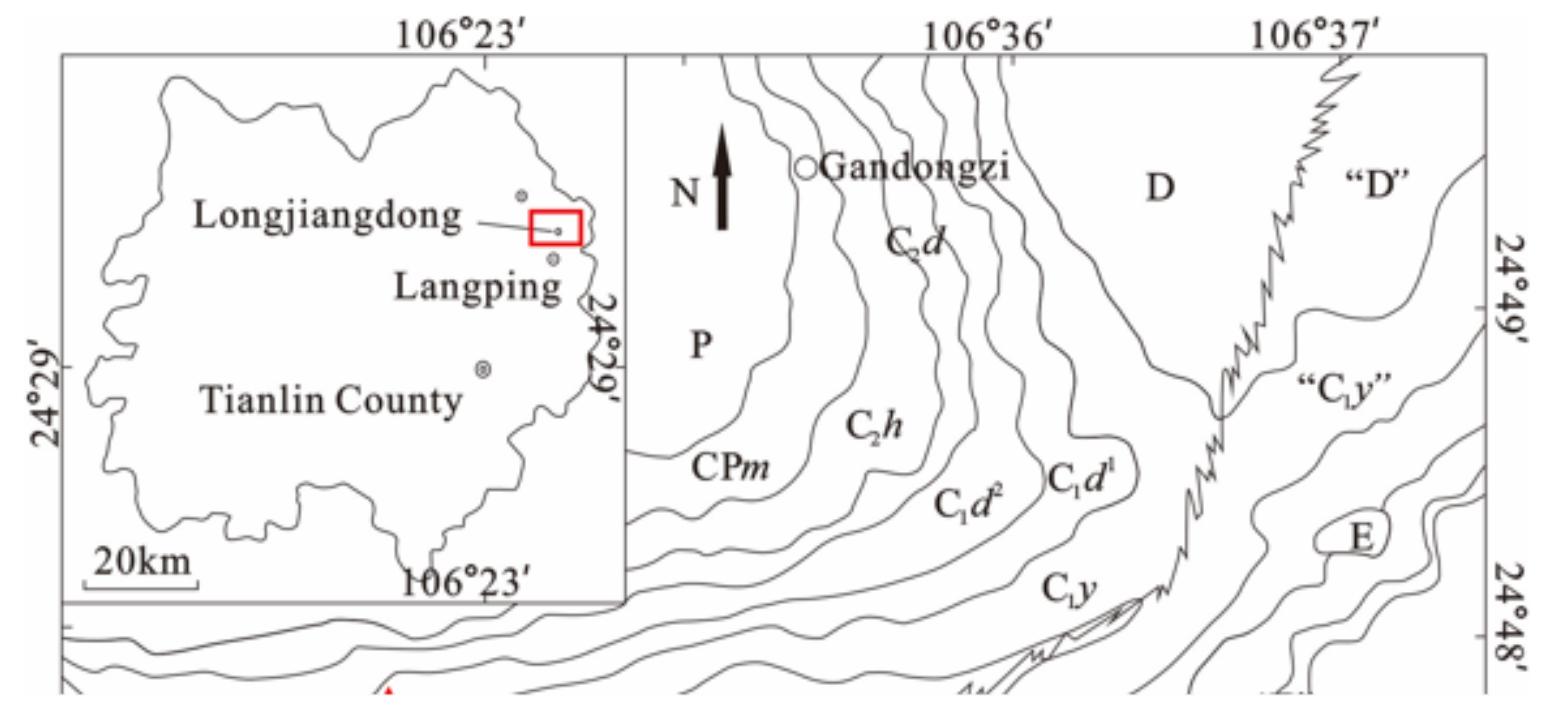

Figure 1

Geological map with coral reef outcrops in the study area 


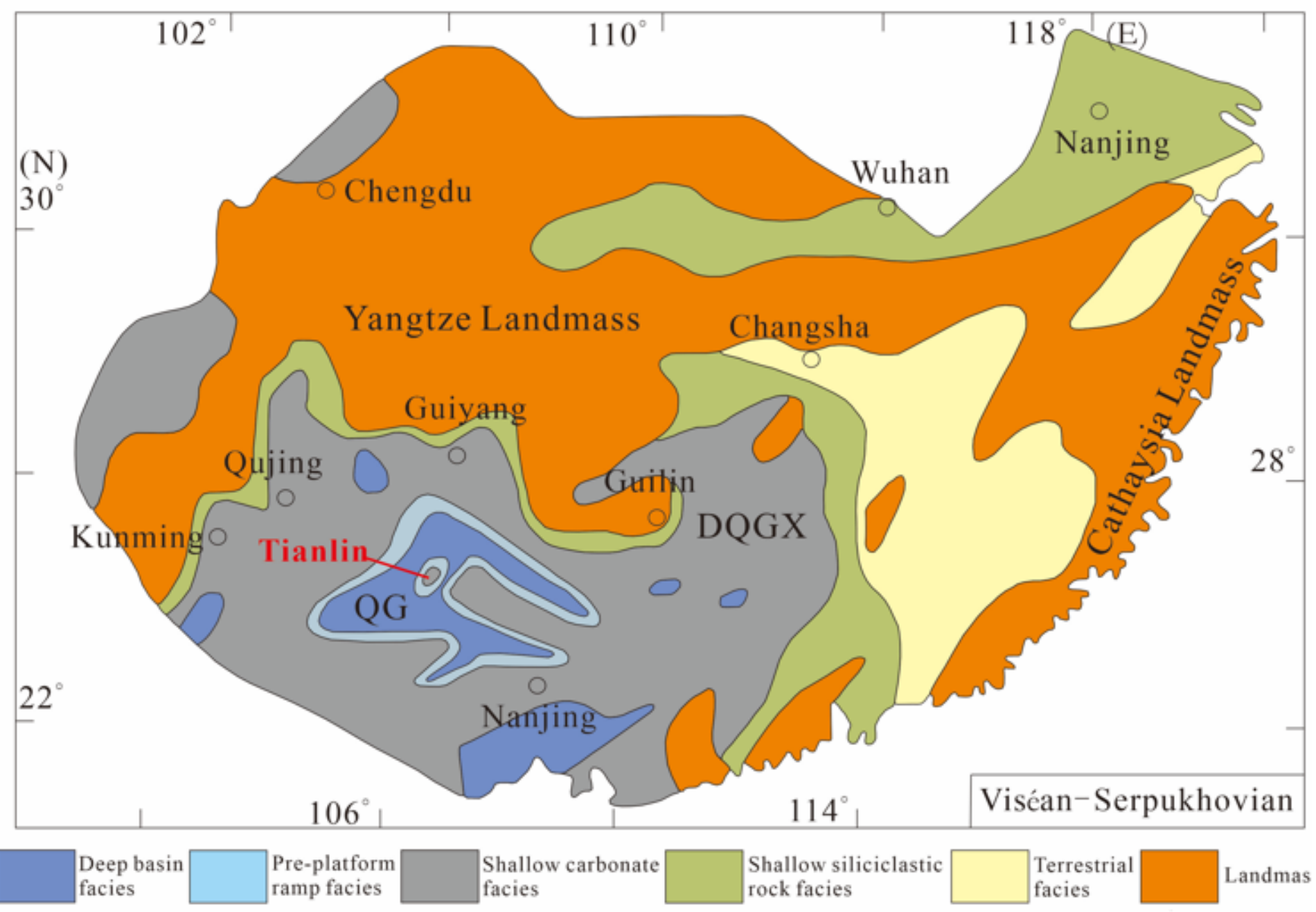

\section{Figure 2}

Paleogeographic map of southern China in Viséan-Serpukhovian (modified from Feng ${ }^{[22]}$ and Yao ${ }^{[23]}$ ) QG: Qian-Gui Basin; DQGX: Dian-Qian-Gui-Xiang platform;

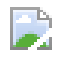

Figure 3

Clastic beaches in the Langping

Various clastic beaches developed in the study area. Diverse composition, fragmentation degree and sorting of the clast indicate different water conditions of formation. 


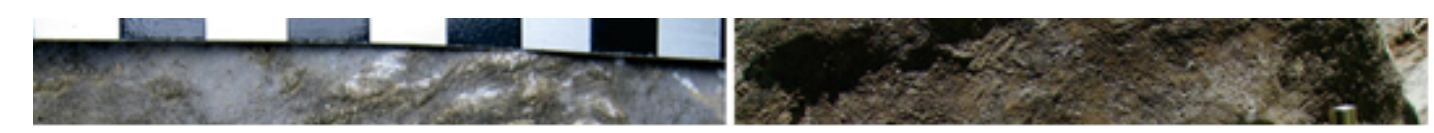

\section{Figure 4}

Algae bondstone in the Langping

Bondstone formed by various algaes living in still water. Morphology of bondstone correlates water environment and deposition of mud. Vast algal boundstones indicate deep water and high deposition rate. 

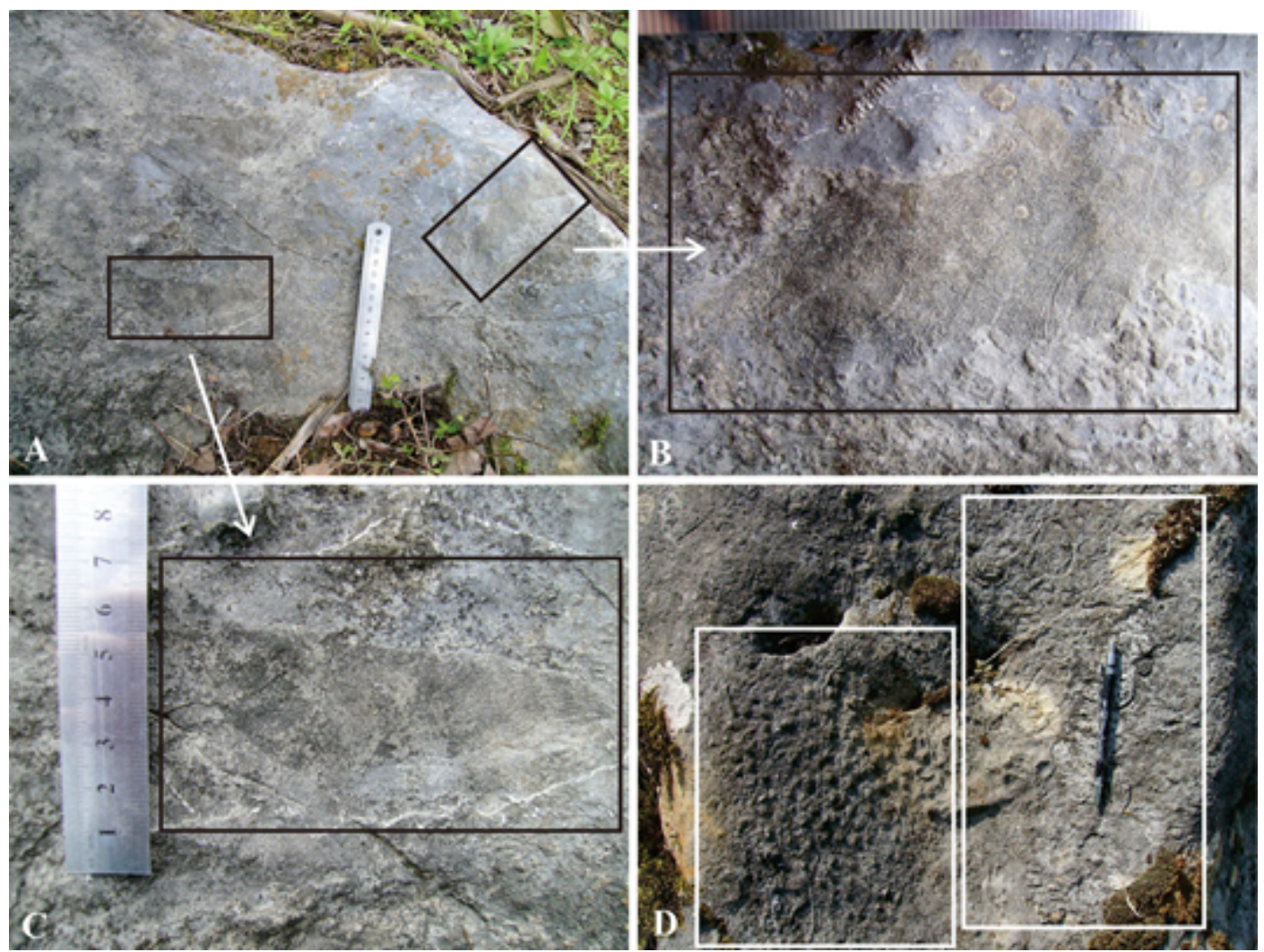

\section{Figure 5}

Different species occupied the discontinuity surface irregularly.

(A) Different reef-builders colonized and grew on the same hard substrate. (D) Colony corals and a large number of individual corals grew together in a limited area, indicating equal colonization at newly formed discontinuity surface. 


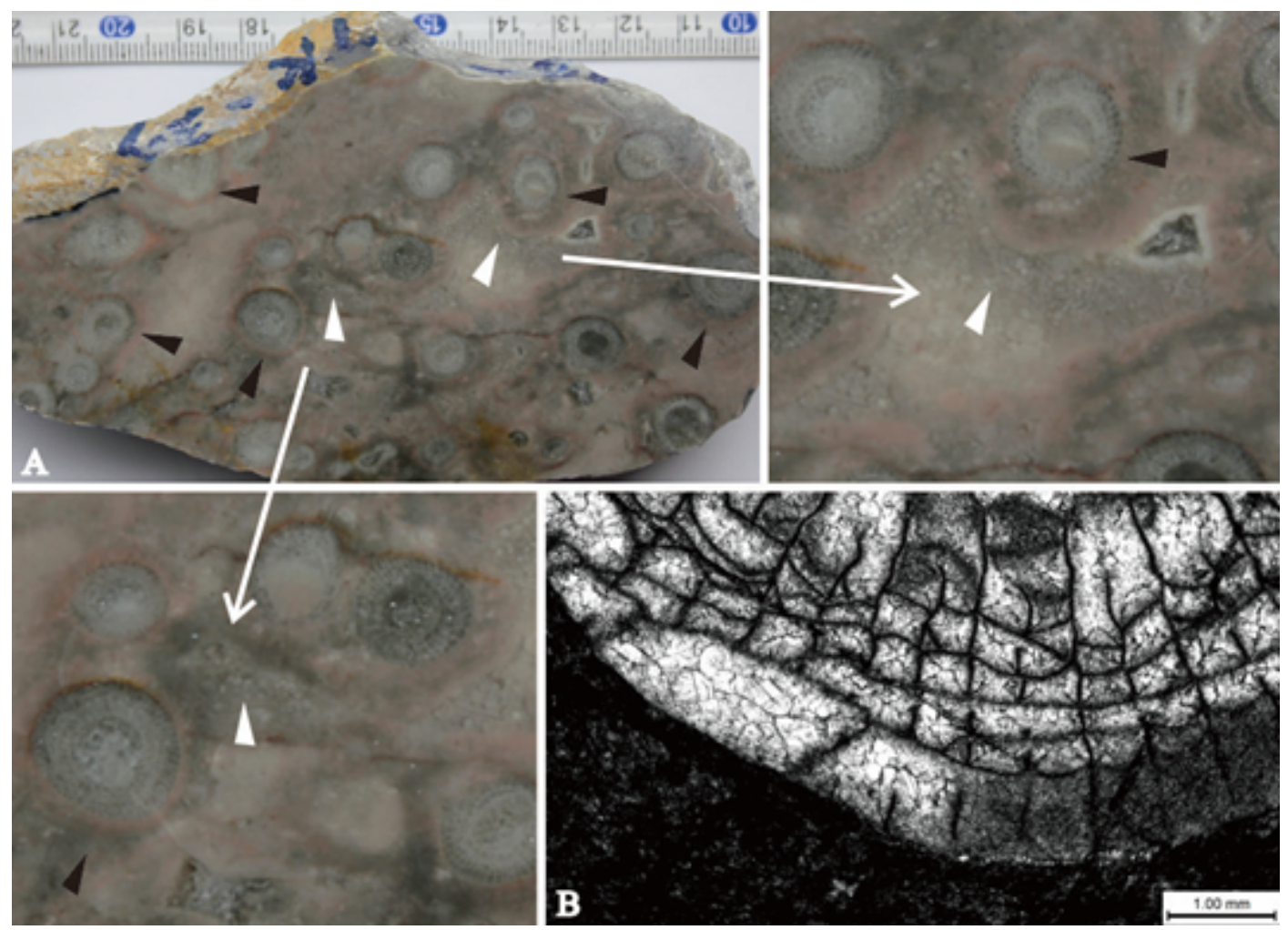

Figure 6

Micrographs of microbes and algaes

(A) Encrustations (indicated by black arrows) with distinct thickness around coral clusters formed by microbe and algal mats through bonding mud. The encrustations were formed before the clastic deposition (indicated by white arrows), showing the corals were living then. Microbes and algaes inside of the dense coral clusters had little impact on corals. (B) Single polarized micrograph showed clear and smooth boundaries of coral individuals without encrustation or drilling hole made by microbes or algaes. Few corals surrounded by bonding algaes could be observed in Langping, indicating that algaes were poorly developed between coral clusters. 

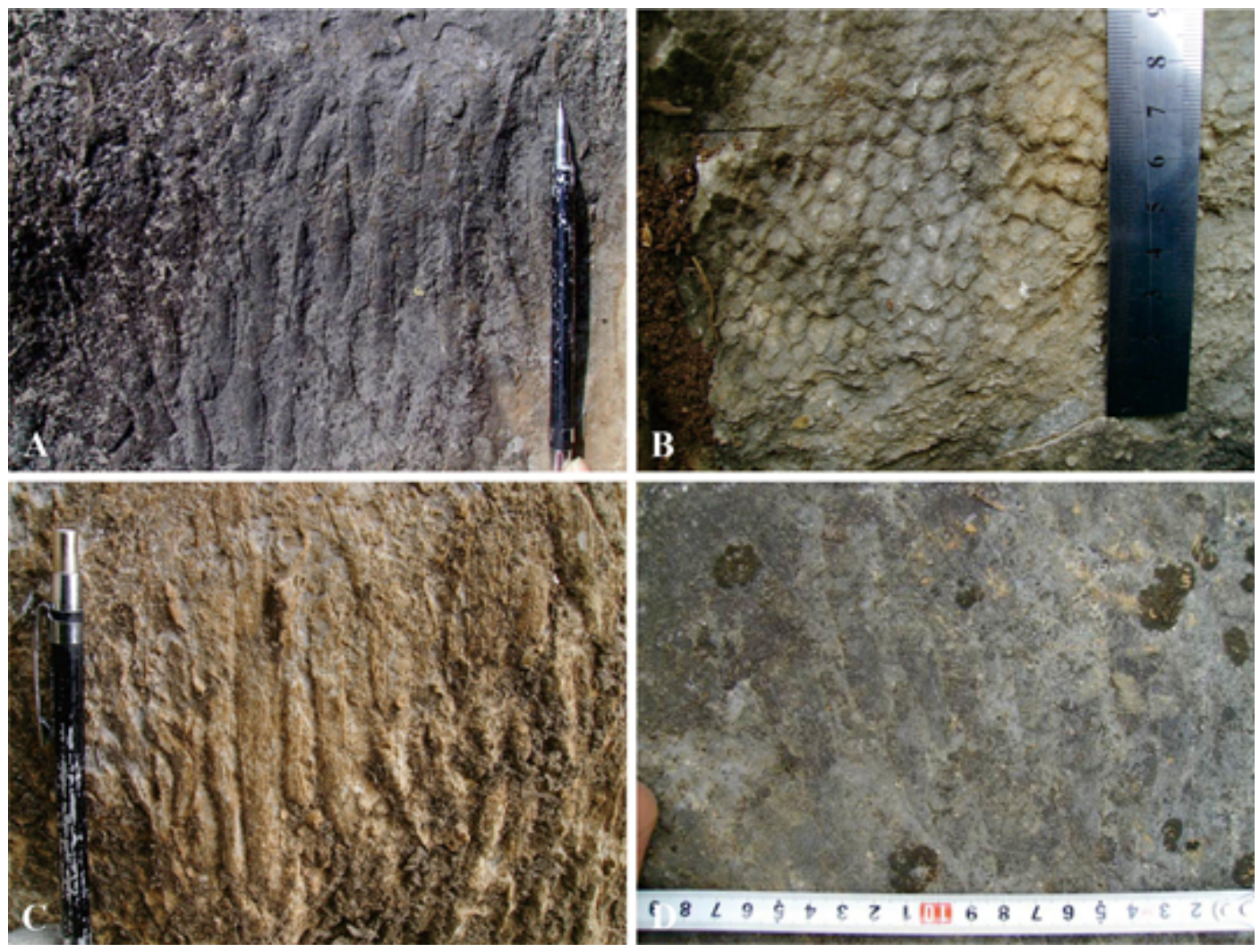

\section{Figure 7}

Main reef-building corals in the study area

(A) Diphyphyllum, (B) Lithostrotion, (C) Siphonodendron, (D) Lonsdaleia

(A) rapidly grew clusters of main reef-building corals. The strong individuals are packed tightly when growing to support each other. 